\title{
Tuberculosis masquerading carcinoma cervix and carcinoma endometrium: 2 case reports
}

\author{
Pinkey Lakra' ${ }^{*}$, Richa Kansal ${ }^{1}$, Vijayata Sangwan ${ }^{1}$, Sunita Siwach ${ }^{1}$, Parveen Rana ${ }^{2}$, \\ Rajiv Mahendru ${ }^{1}$
}

\author{
${ }^{1}$ Department of Obstetrics and Gynaecology, BPS, GMC, Khanpurkalan Sonipat, Haryana, India \\ ${ }^{2}$ Department of Pathology, BPS, GMC, Khanpurkalan, Sonipat, Haryana, India
}

Received: 29 August 2016

Accepted: 28 September 2016

\section{*Correspondence:}

Dr. Pinkey Lakra,

E-mail: drpinki_18@yahoo.com

Copyright: (C) the author(s), publisher and licensee Medip Academy. This is an open-access article distributed under the terms of the Creative Commons Attribution Non-Commercial License, which permits unrestricted non-commercial use, distribution, and reproduction in any medium, provided the original work is properly cited.

\begin{abstract}
Tuberculosis is a common infection in developing countries but genital tuberculosis is less common, confused with malignancy and difficult to diagnose at times. We present 2 cases of genital tuberculosis where a clinical diagnosis of malignancy was made and tuberculosis surprised us once again. This case report is intended to emphasize to suspect tuberculosis in young patients on the basis of history and examination to be later supported by investigations.
\end{abstract}

Keywords: Carcinoma cervix, Tuberculosis, Pyometra

\section{INTRODUCTION}

Tuberculosis has been notorious in its course through history both by its persistence defying all efforts by mankind to eradicate it over the centuries and by its varied and atypical manifestations. To the dillema is added the fact that the diagnosis is not always clear despite the use of all sophisticated investigation currently available. Clinical suspicion plays a vital role in diagnosing and managing these patients.

Genital tuberculosis is mostly secondary to a primary focus elsewhere and rarely a primary disease. There may be a positive personal or a family history of tuberculosis and it should always be kept as a differential diagnosis in cases suspicious of gynaecologic malignancy. Although most of the cases are from females of reproductive ages only, it has also been reported in post menopausal individuals also. Culture methods are still the gold standard in the detection of genital tuberculosis but they are negative in about one-third of cases. ${ }^{1}$ In such cases there is a role of demonstration of granuloma on histopathologic examination. Highman in a study indicated that pap smears may be helpful in making diagnosis of tubercular endometritis with the presence of epitheloid cells especially in second half of the menstrual cycle. $^{2}$ Newer diagnostic tests of DNA PCR may prove to be promising in case of strong suspicion although they are less specific.

\section{CASE REPORT}

CASE 1: Tubercular cervical ulcer mimicking carcinoma cervix

A 30 years old para 4 presented to the Gynae OPD with yellowish discharge per vaginum for 6 months and post coital bleeding for 2 months. The discharge foul smelt and not associated with itching. There was a positive history of weakness and weight loss but no history of evening rise of temperature. She also had a family history of pulmonary tuberculosis in a close contact that was on ATT for 4 months. On further evaluation her menstrual cycles were normal. On general physical examination she 
was thin built with height $150 \mathrm{~cm}$ and weight $47 \mathrm{~kg}$ and abdominal examination was normal. There was no lymphadenopathy. Per speculum examination revealed an ulcerative growth on anterior lip of cervix of approximately $2 \times 2 \mathrm{~cm}$ size with moderate amount of discharge and on per vaginum examination it was friable and bleeding on touch apparently suggesting cancer cervix. Uterus was normal in size and bilateral fornices were clear. Punch biopsy was taken from the growth and histopathology revealed tubercular cervicitis and $20 \%$ $\mathrm{H}_{2} \mathrm{SO}_{4}$ stain positive for acid fast bacilli. Other investigations like complete blood count, viral markers, montoux, sputum for acid fast bacilli and chest $\mathrm{x}$ ray were normal. Ultrasongraphy showed normal uterus and adnexa with $7 \mathrm{~mm}$ endomertial thickness. Patient was put on Category 1 dots and she came for follow up after 4 months with a normal per speculum examination.

\section{CASE 2: Endometrial tuberculosis in menopausal women}

A 50 year old menopausal multiparous woman came to the OPD with chief complaints of pus like discharge per vaginum for 1 year. It was associated with generalised weakness and significant weight loss of $8 \mathrm{~kg}$ over 1 year. There was no history of postmenopausal bleeding. Per speculum examination showed an atrophic and congested cervix and on per vaginum examination uterus was soft, retroverted and normal size. On sonography there was a mild collection in endometrial cavity with endometrial thickness of $10 \mathrm{~mm}$. Her complete blood count was normal and viral markers were non-reactive. Endometrial and endocervical sampling was done which showed necrotizing epitheloid cell granuloma suggestive of tuberculosis and AFB staining with $20 \% \mathrm{H}_{2} \mathrm{SO}_{4}$ positive. Montoux was $16 \mathrm{~mm}$, chest $\mathrm{X}$-ray was normal and sputum for acid fast facilli was negative. Category 1 dots were given for 6 months and ultrasound done on completion of treatment showed a normal uterus with endometrial thickness of $3.5 \mathrm{~mm}$ and no adnexal mass.

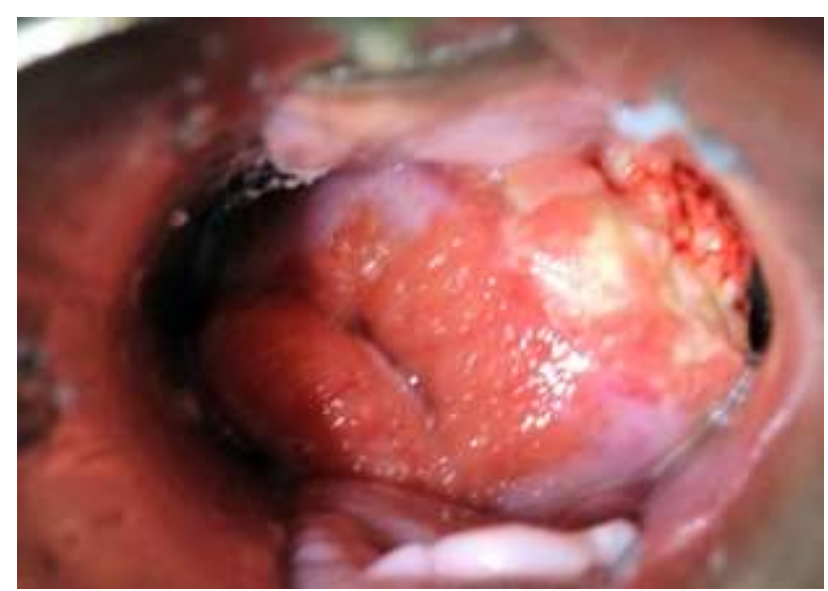

Figure 1: Colposcopic picture of the malignant looking growth on the anterior lip of cervix.

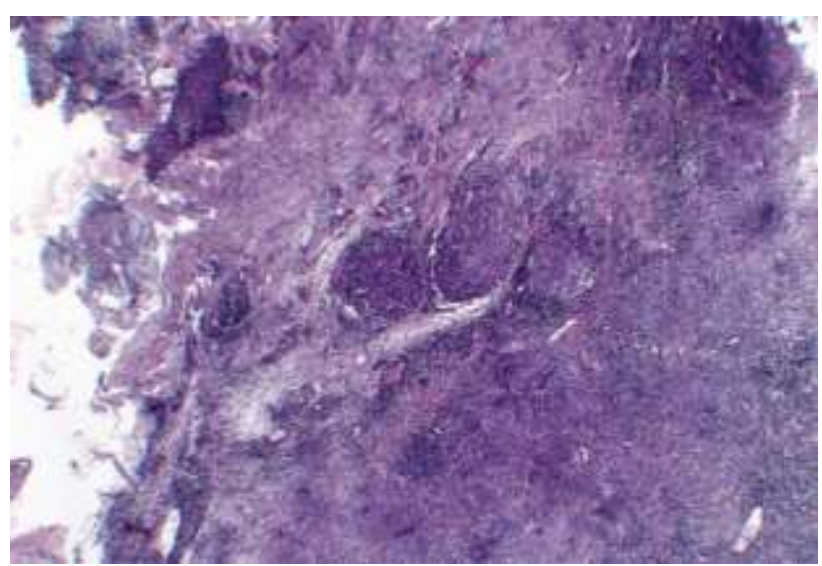

Figure 2: Necrotizing granulomas on cervical biopsy suggesting tuberculous cervicitis.

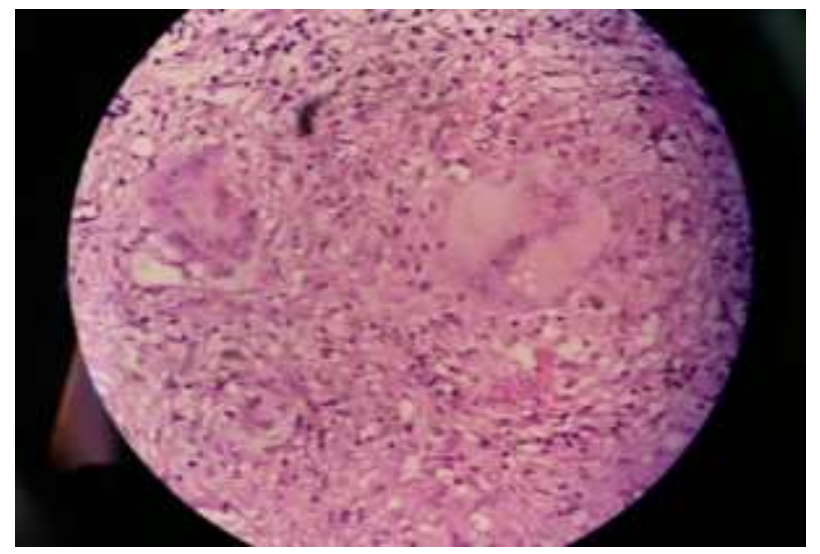

Figure 3: Necrotizing epitheloid cell granuloma of endometrium of postmenopausal woman.

\section{DISCUSSION}

Tuberculosis is a chronic infectious disease and still a serious health issue worldwide. About 8 million people develop active TB, with 1.6 million dying each year because of TB according to the World Health Organization. ${ }^{3}$ Pulmonary tuberculosis is a major disease burden even in today's era but genital tuberculosis is not so common. Genital organs affected most commonly with tuberculosis are fallopian tubes followed by endometrium, ovaries, cervix, vagina and vulva. Tuberculosis of cervix constitutes $0.1 \%-0.65 \%$ of all tuberculosis cases. ${ }^{4}$ Endometrial tuberculosis is usually found in reproductive age group mostly as a cause of infertility in $10 \%$ of infertile women but quite rare in post menopausal women. Pyometra has a reported incidence of $0.01 \%-0.5 \%$ in gynecologic patients and common causes are atrophic endometritis followed by endometrial cancer, cervical cancer and rarely endometrial tuberculosis. ${ }^{5}$ Post menopausal women with endometrial tuberculosis mostly present with post menopausal bleeding and tubercular pyometra is extremely rare. An atrophic endometrium which has poor vascular support to the growth of Mycobacterium could be a possible explanation, though exact reason is not known. ${ }^{6}$ 
Grossly cervical tuberculosis may have papillary or vegetative growths, a miliary appearance, and/or ulceration thus simulating invasive cervical cancer. ${ }^{7-10}$ The diagnosis of cervical and endometrial TB is usually made by histological examination of biopsy specimen. ${ }^{7,10}$ Staining of acid fast bacilli is also diagnostic as in both of our cases but in one study, it was not found to be very useful in making the diagnosis. ${ }^{11}$ A retrospective review found that ulcerative lesions usually are auramine negative. ${ }^{12}$ The detection of granulomata on cervical cytology specimens has also been documented. ${ }^{2,13,14}$ Isolation of the mycobacterium is the gold standard for diagnosis but about one third of cases are culture negative. ${ }^{1,15}$ Therefore, the presence of typical granulomata is sufficient for diagnosis if other causes of granulomatous lesions such as Chamydia trachomatis, Neisseria Gonorrhoea etc. are excluded or a primary focus identified. Molecular probes may be more sensitive than culture but also have reduced specificity. If biopsy is unequivocal for $\mathrm{TB}$, then one must still be vigilant and proceed with rapid new diagnostic marker tests like TB PCR for detection of Mycobacterium tuberculosis DNA, with the help of which it is now possible to pick up even latent endometrial/endocervical tuberculosis. ${ }^{16}$ Similar conclusion was made by Kulshrestha et al in which a quarter of women with infertility received ATT solely on the basis of PCR and $31 \%$ of these women conceived. ${ }^{17}$

Many studies in countries with a high TB incidence have shown that the prevalence may reach. $5 \%$ or more among contacts, particularly among household members. ${ }^{18}$ Here there may be a role of contact tracing and investigating the close contact with montoux test, chest X-ray and sputum smear examination. Category I short course chemotherapy for 6 to 9 months has been found to effective treatment and both of our patients responded well to it.

\section{CONCLUSION}

A high suspicion can be recommended in patients of reproductive age group with cervical tuberculosis and post-menopausal pyometra especially in developing countries where burden of tuberculosis is high and also those who have a close contacts with pulmonary or may be extra pulmonary tuberculosis.

\section{Funding: No funding sources Conflict of interest: None declared Ethical approval: Not required}

\section{REFERENCES}

1. Agrawal S, Madan M, Leekha N, Raghunandan C. A rare case of cervical tuberculosis simulating carcinoma cervix: a case report. Cases J. 2009;2:161.

2. Highman WJ. Cervical smears in tuberculous endometritis. Acta Cytol. 1972;16:16-20.

3. Sharma JB, Roy KK, Pushparaj M, Gupta N, Jain SK, Malhotra N. Genital tuberculosis: an important cause of Asherman's syndrome in India. Arch Gynecol Obstet. 2008;277:37-41.

4. Lamba H, Byrne M, Goldin R, Jenkins C. Tuberculosis of the cervix: case presentation and a review of the literature. Sex Transm Infect. 2002;78:62-3.

5. Chan LY, Lau TK, Wong SF, Yuen PM. Pyometra. What is its clinical significance? J Reprod Med. 2001;46:952-6.

6. Maestre MA, Manzano CD, López RM. Postmenopausal endometrial tuberculosis. Int $\mathrm{J}$ Gynaecol Obstet. 2004;86:405-6.

7. Koller AB. Granulomatous lesions of the cervix uteri in black patients. South Afr Med J.1975;49:1228-32.

8. Carter J, Peat B, Dalrymple C, Atkinson K. Cervical tuberculosis - case report. Aust NZ J Obstet Gynaecol. 1989;29:270-1.

9. Kobayashi-Kawata T. Tuberculous cervicitis. Acta Cytol. 1978;22:193-4

10. Sobin D, Sall S, Pellman C. Genitourinary tuberculosis simulating cervical carcinoma. J Reprod Med. 1976;17:305-8.

11. Agarwal J, Gupta JK. Female genital tuberculosis-a retrospective clinico-pathologic study of 501 cases. Indian J Pathol Microbiol. 1993;36:389-97.

12. Chakraborty P, Roy A, Bhattacharya S, Addhya S, Mukherjee S. Tuberculous cervicitis: a clinicopathological and bacteriological study. J Indian Med Assoc.1995;93:167-8.

13. Shobin D, Sall S, Pellman C. Genitourinary tuberculosis simulating cervical carcinoma. J Reprod Med.1976;17:305-8.

14. Sutherland AM, Glen ES, MacFarlane JR. Transmission of genito-urinary tuberculosis. Health Bull. 1982;40:8791.

15. Samantaray S, Parida G, Rout N, Giri SK, Kar R. Cytologic detection of tuberculosis cervicitis: a report of seven cases. Acta Cytol. 2009;53(5):594-6.

16. Shetty J, Kumar P, Ramkumar V. Management of female genital tuberculosis, reappraised. Obst and Gynae Today. 2006;11(a):506-09.

17. Kulshrestha V, Kriplani A, Agarwal N, Singh UB, Rana T. Genital tuberculosis among infertile women and fertility outcome after antitubercular therapy. Int J Gynaecol Obstet. 2011;113(3): 229-34.

18. World Health Organization. Recommendations for investigating contacts of persons with infectious tuberculosis in low and middle-income countries. Geneva: who, 2012.Web 15 July 2012.

Cite this article as: Lakra P, Kansal R, Sangwan V, Siwach S, Rana P, Mahendru R. Tuberculosis masquerading carcinoma cervix and carcinoma endometrium: 2 case reports. Int J Reprod Contracept Obstet Gynecol 2016;5:4079-81. 